\title{
INTELIGÊNCIA EMOCIONAL: TESTANDO A ENFERMAGEM DO FUTURO'
}

\author{
EMOTIONAL INTELLIGENCE: TESTING THE NURSING OF THE FUTURE \\ INTELIGENCIAEMOCIONAL: AQUILATANDO LAENFERMERIADEL \\ FUTURO
}

\author{
Laina Maiza dos Santos ${ }^{2}$ \\ Francismeuda Lima de Almeida ${ }^{2}$ \\ Stefánia da Costa Lemos²
}

\begin{abstract}
RESUMO: Para termos uma visão profissional prospectiva, objetivamos traçar o perfil dos acadêmicos de Enfermagem para um padrāo de Inteligência Emocional e identificar suas aptidōes cognitivas, comportamentais e emocionais, considerando que ser emocionalmente inteligente está se tornando requisito imprescindivel para todo profissional. Estudo exploratório descritivo, realizado numa instituição pública da cidade de Fortaleza-CE, com os estudantes regularmente matriculados no periodo de 99.1, tendo uma amostra de 138 sujeitos. Para isto, utilizamos um questionário composto por um teste disponivel na internet e uma segunda parte de perguntas acerca das aptidões emocionais, cognitivas e comportamentais relacionadas a Inteligência Emocional. Como resultados, obtivemos que a maioria dos estudantes $(78,26 \%)$ tem um bom nivel de Inteligência Emocional e apenas $16,67 \%$ merecem aprimoramento. Na distribuiçăo das aptidōes emocionais, cognitivas e comportamentais como suficientes, regulares e insuficientes, as aptidōes cognitvas se destacaram entre as demais. Concluimos principalmente que os estudantes tem potencial para serem profissionais empáticos, sintonizados com os pacientes e capazes de saber e se fazer ouvir, caracteristicas básicas da Inteligência Emocional.
\end{abstract}

PALAVRAS CHAVE: inteligência emocional, educação em enfermagem.

\section{INTRODUÇÄO}

Uma análise social por mais superficial que seja nos mostra uma sociedade emocionalmente doente: crimes, suicidios, abuso de drogas... Isto reflete o processo em que se estruturou a base da modernização, que valoriza o conhecimento objetivo e a repressão das emoções.

A história das civilizações evidencia que nos últimos quinhentos anos, o homem dissociava a emoção do raciocínio lógico em seus momentos de decisão. O pressuposto era que o individuo enquanto ser racional deveria ter o domínio absoluto da razão e desvincular qualquer tipo de sentimento sob pena de prejudicar suas atitudes.

Sobre esta dissociação entre razão e emoção, Moscovici (1997, p.25) enfatiza que isto vem sendo perpetuado através da educação:

"Este lado emocional tem sido negligenciado através dos tempos. A começar pelas familias. Nestas, não se dá uma educação emocional às crianças. Nos preocupamos, como pais, em dar uma educação

\footnotetext{
'Prêmio Marina de Andrade Rezende. $1^{\circ}$ lugar, 51CBEn

${ }^{2}$ Alunas do Curso de Graduação em Enfermagem. Universidade Federal do Ceará
} 
social baseada em regras de comportamento e conduta, ou seja, nós passamos as convenções sociais para as nossas crianças, baseados em uma certa lógica: tudo que é aceito por nossa sociedade (processo cultural). Enfim, nos preocupamos muito pouco com a parte emocional, de realmente desenvolver a maneira de expressar as emoções e lidar com elas. Esta falha de educação familiar infantil prossegue na escola, que também não se preocupa; os professores. desde o jardim de infância, não se preocupam com o lado emocional."

Hoje já se admite que o controle das emoções é fator essencial para o desenvolvimento da inteligência do individuo e esta não é uma habilidade puramente cognitiva. GOLEMAN (1995) apresenta sua teoria que redefine o que é ser inteligente e de acordo com seus pressupostos podemos afirmar que Inteligência Emocional é a capacidade de criar motivações para si próprio e de persistir num objetivo apesar dos obstáculos; de controlar impulsos e saber aguardar pela satisfação de seus desejos; de se manter em bom estado de espirito e de impedir que a ansiedade interfira na capacidade de raciocinar, de se relacionar bem, ser empático e autoconfiante.

O sucesso individual é algo almejado por todos. E muitos atribuem-no ao quociente de inteligência (QI) e esse, por sua vez, ao bom desempenho escolar e acadêmico. No entanto, muito se questiona estas atribuiçőes quando acontece de pessoas com alto quociente de inteligência não se sairem bem na carreira, enquanto que pessoas sem essa classificação alcançam o auge. Saber que uma pessoa é um excelente aluno é saber apenas que ela é muito boa na obtenção de notas altas. Nada nos diz de como ela reage as vicissitudes da vida. Pessoas com alto nivel de QI podem ser incompetentes na administração de sua vida particular. Quanto aos testes de inteligência, umas das maiores dificuldades colocadas para sua validação é como aferir, em um determinado momento, algo que é um processo contínuo? Outra seria a fins de definição, pois inteligente seria aquela pessoa que tem bons resultados nos testes de inteligência? Além da limitação nos aspectos abordados, existe também a subjetividade que fica implicita.

Através da experiência ou do aprendizado não existe muita possibilidade de se alteraro QI, enquanto que as aptidões emocionais podem ser aprendidas e aprimoradas ao longo o desenvolvimento do indivíduo. Assim, cada um teria duas inteligências. A primeira, que é mensurada pelos testes tradicionais de QI, está mais relacionada ao raciocínio e à lógica. Sendo que essa medida ignora completamente a capacidade da pessoa relacionar-se com os outros, suas aptidões de liderança, sua criatividade e flexibilidade para adaptar-se às diversas situações da vida. E a segunda inteligência é a emocional, definida anteriormente.

No entanto, em meio a estas diferenciaçöes, Cavicchini (1994, p.26) esclarece:

"Um alto QI, pelo menos na teoria, garante que o indivíduo seja intelectualmente eficiente e que tenha uma considerável fluência verbal e permite que ele possa resolver problemas através de modelos lógicos com facilidade e elegância. Já uma elevada IE assegura ao seu portador boa comunicação, empatia, ótima convivência social, notável capacidade de engajamento, além de solidariedade, responsabilidade e ética invejáveis. É importante ressaltar, entretanto, que o Quoeficiente de Inteligência e a Inteligência Emocional não são conceitos opostos; são apenas diferentes e, em certa medida, até complementares. Assim, o ideal seria que cada pessoa pudesse atingir um alto nivel de IE, tendo como base um QI satisfatório." 
Considerando o compromisso social da profissão de enfermagem, acreditamos que o nosso trabalho venha despertar na comunidade acadêmica o interesse no desenvolvimento dessa aptidão, uma vez que a sociedade espera por profissionais preparados para enfrentar o caos em que se encontra, como nos mostra o panorama mundial: o sentimento de solidão das pessoas; a violência conjugal; um aumento, a nivel mundial, dos casos de depressão; convivência com culturas diferentes devido a globalização; individualismo exacerbado, o que acarreta uma competitividade cada vez maior nos postos de trabalho e no meio universitário; isolamento e deteriorização das relações sociais; a lenta desintegração da vida em comunidade; as pressões econômicas e sociais; e os indicadores de um crescente desconforto emocional, sobretudo entre as crianças.

Diante disso, nos motivamos a desenvolver um estudo que fomente discussões sobre esta temática voltadas para a Enfermagem, pela notável necessidade de desenvolver uma inteligência emocional nesta profissão. Pois sabemos que esta exige alto controle de emoções, por lidar com vidas; pelas suas atividades merecerem alta concentração; além de ter extrema restrição do "luxo" de enrar.

Em qualquer profissão existem desafios a serem enfrentados, e o profissional inteligente é aquele que não tem medo de superá-los. Na Enfermagem, o desafio maior é conseguir o reconhecimento da sociedade, mas para isso o enfermeiro deve primeiro reconhecer-se como pessoa, capaz e competente, e que deve ter equilibrio emocional para trabalhar com uma equipe.

Vivemos no mundo da auto-suficiência, achando muitas vezes que podemos resolver tudo sozinhos. No entanto, as melhores ações são aquelas feitas em conjunto. Algumas conquistas importantes só são alcançadas se nos unirmos aos outros. Destacando neste contexto a Enfermagem e seu trabalho em equipe, ressaltamos que a necessidade de delegar ações não divide a conquista do mérito e sim caracteriza um profissional emocionalmente inteligente.

O lazer também é bastante útil ao equilibrio emocional de uma pessoa. O trabalhador precisa liberar o estresse e a tensão de um dia que exige dele agilidade e raciocínio. Divertir-se, sorrir, descansar, relaxar, enfim, são condiçőes essenciais para que uma pessoa possa ser feliz e capaz de ser criativa no seu próximo trabalho.

Escolher bem a profissão que vamos seguir carreira cabe a cada um. Entretanto, às vezes, alguns valores nos colocam diante de escolhas não favoráveis às nossas aptidōes e o resultado é a formação de um profissional frustado que não consegue crescer dentro do seu trabalho. Então, vive melhor emocionalmente aqueles que fazem o que gostam e, assim, conseguem crescer profissionalmente.

Considerando-se que não existe mais espaço para o profissional que não consegue desenvolver habilidades de compreender como se efetuam os mecanismos de manejo relacionados ao controle, estabilização e utilização das emoções, objetivamos com este estudo traçar o perfil dos acadêmicos de Enfermagem para um padrão de Inteligência Emocional e identificar suas aptidões cognitivas, comportamentais e emocionais, para termos uma visão deste profissional do futuro.

\section{METODOLOGIA}

Com a difusão de discussões sobre Inteligência Emocional nos meios de comunicação e suas implicaçöes nas carreiras profissionais, consideramos pertinente realizarmos um estudo sobre $o$ assunto, situando a enfermagem neste contexto, na perspectiva da formação acadêmica. Assim, pela natureza recente da temática, caracterizamos nosso estudo como do tipo exploratónio descritivo que segundo Lakatos e Marconi (1995, p.188): "são aqueles que têm por objetivo descrever completamente determinado fenômeno, como, por exemplo, o estudo de um 
caso para o qual são realizadas análises empíricas e teóricas. Podem ser encontradas tanto descrições quantitativas e/ou qualitativas quanto acumulação de informações detalhadas com as obtidas por intermédio da observaçăo participante."

A população foi composta por acadêmicos de Enfermagem de uma instituição pública na cidade de Fortaleza-CE, regularmente matriculados no período 99.1, representando um total de 358 discentes. E a amostra foi composta por 138 acadêmicos, correspondente a $38,6 \%$ da população, escolhidos de forma aleatória. Todos os periodos da graduação foram contemplados. Porém, uns com maior representatividade que outros, pois o número de estudantes para cada periodo varia muito de acordo com as disciplinas cursadas, além da inviabilidade dos estudantes que se encontravam em campo de estágio, dificultando igualar o número de participantes de cada período e também a coleta de dados.

Os dados foram coletados no decorrer do primeiro semestre do ano de 1999, utilizandose como instrumento de coleta de dados um questionário que foi composto por duas partes: a primeira constou de um teste para avaliar a Inteligência Emocional disponivel no endereço http://www.gold.com.br/ floreser/qe.html e a segunda, foi construida para identificar aptidões emocionais, cognitivas e comportamentais listadas segundo Goleman (1995). Apesar das criticas aos testes de inteligência já mencionadas, justificamos a utilização desse subsidio por não se ter ainda outra forma mais adequada que possibilitasse $o$ alcance dos nossos objetivos.

A segunda parte do instrumento foi dividida em blocos de acordo com os conjuntos das aptidões consideradas, e para cada um destes, construimos intervalos, seguindo o número de respostas positivas. Para classificarmos os sujeitos da pesquisa quanto a estas aptidões, não encontramos respaldo na literatura, mas arbitramos como aptidões suficientes, regulares e insuficientes, sendo da seguinte maneira: para o bloco das Aptidões Emocionais, em número de oito, estipulamos que um número de respostas positivas inferior ou igual a três seria considerado como quantidade insuficiente para um padrão eficiente de Inteligência Emocional; de quatro a seis, quantidade regular e mais de seis, quantidade suficiente. O bloco das Aptidões Cognitivas continha seis aptidōes. Assim, utilizamos as mesmas definições, porém para intervalos diferentes, que foram: até dois, de três a quatro e mais de quatro, respectivamente. Como as Aptidões Comportamentais eram em número de quatro, consideramos apenas duas definições, insuficientes e suficientes, para os intervalos de até dois e mais de dois, respectivamente.

Os dados da Parte I foram tabulados de acordo com o gabarito sugerido no referido site, que omitimos na elaboração do instrumento, mas expomos a seguir.

\section{VALORES DAS RESPOSTAS}
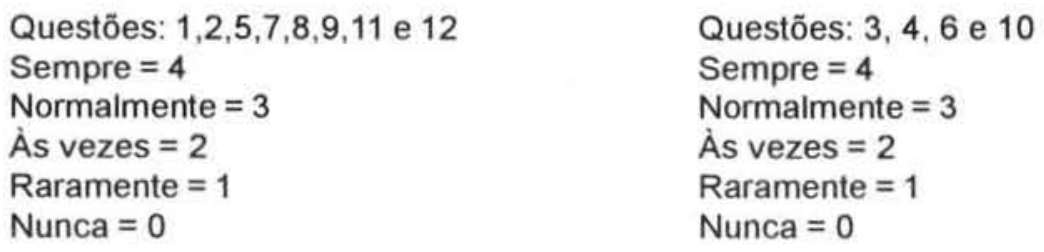

\section{RESULTADO}

Acima de 36 pontos: Você provavelmente tem uma inteligência emocional superior De 25 a 35 pontos: Você tem um bom nivel de inteligência emocional Menos de 24 pontos: Merece aprimoramento 
Para a tabulação dos dados da Parte II nos baseamos no número de respostas positivas e construimos a seguinte escala de valores:

\section{APTIDÕESEMOCIONAIS}

Menor ou igual a 3 : Insuficiente

4-6: Regular

Mais de 6: Suficiente

\section{APTIDÖES COGNITIVAS}

Até duas: Insuficiente

3-4: Regular

Mais de 4 : Suficiente

\section{APTIDÕES COMPORTAMENTAIS}

Até duas : Aptidão Insuficiente

Mais de duas : Aptidão Suficiente

Os dados foram tabulados e os resultados organizados em quadros e tabelas, sendo seguidamente analisados e discutidos .

\section{ANÁLISE E DISCUSSÃO DOS RESULTADOS}

PARTE I : Avaliação da Inteligência Emocional

TABELA 1. Distribuição dos acadêmicos de Enfermagem em relação a sua Inteligência Emocional. Fortaleza-CE, 1999

\begin{tabular}{lcc}
\hline SITUAÇÕES & f & $\%$ \\
\hline Provavelmente tem uma Inteligência Emocional superior & 07 & 5,07 \\
Tem um bom nivel de Inteligência Emocional & 108 & 78,26 \\
Merece aprimoramento & 23 & 16,67 \\
\hline TOTAL & 138 & 100,00 \\
\hline
\end{tabular}

A tabela 01 nos mostra que a maioria dos estudantes $(78,26 \%)$ se encontra na situação II, ou seja, tem um bom nivel de Inteligência Emocional. Este bom nível de Inteligência Emocional que se percebeu na nossa amostra nos faz acreditar na competência destes futuros profissionais, garantindo assim sua adequação às atuais exigências no mercado, uma vez que a Inteligência Emocional está adquirindo peso cada vez maior nos processos seletivos e se tornando fator determinante nas promoçőes de cargo.

A segunda maior porcentagem está na situação III, que segundo a pontuação estabelecida, merece aprimoramento na sua Inteligência Emocional. Embora com uma representatividade de $16,67 \%$ sabemos que existem pessoas menos competentes emocionalmente, mas isto pode estar relacionado ao sistema educacional e familiar em que se desenvolveram, contribuindo 
para que estas desenvolvessem certas respostas emocionais que dificultam o relacionamento intra e interpessoal. Goleman (1995) comenta em seus estudos que estas pessoas possuem alguns hábitos arraigados de expressão emocional, que dificilmente mudam. Elas têm dificuldade para lidar com suas emoções. No entanto, dentro do contexto da enfermagem, estes obstáculos ganham importância ainda maior e precisam ser trabalhados, uma vez que a profissão escolhida envolve o cuidar do ser humano em todas as suas dimensões, exigindo não apenas conhecer o outro mas também a si mesmo.

Ainda na tabela 1 podemos perceber que apenas $5,07 \%$ estão na situação I que, de acordo com a classificação, provavelmente tem um Inteligência Emocional superior. Isto indica que o número de pessoas que conseguem realmente lidar com suas emoçőes ainda é muito limitado, principalmente quando comparado com as porcentagens anteriores.

QUADRO 1. Situação dos acadêmicos de Enfermagem em relação a sua Inteligência Emocional, de acordo com o semestre da graduação. Fortaleza, Ceará, 1999.

\begin{tabular}{|c|c|c|c|}
\hline $\begin{array}{l}\text { Situagóes } \\
\text { Periodos }\end{array}$ & $\begin{array}{l}\text { Provavelmente tem una inteligencia } \\
\text { Emocional superior }\end{array}$ & $\begin{array}{l}\text { Tem tun boin nivel de } \\
\text { Inteligéncia Emocional }\end{array}$ & Mrecte uprimsramento \\
\hline 1 periodo & 03 & 19 & 03 \\
\hline 2 periodo & - & 11 & 05 \\
\hline 3 periodo & - & 08 & 01 \\
\hline 4 periodo & 01 & 10 & 01 \\
\hline $5^{\circ}$ período & - & 15 & 04 \\
\hline 6 periodo & 02 & 14 & 03 \\
\hline $7^{\circ}$ periodo & - & 11 & 02 \\
\hline 8 periodo & - & 14 & 04 \\
\hline 9 periodo & 01 & 06 & - \\
\hline
\end{tabular}

No dia-a-dia da instituição em que realizamos o estudo, os estudantes de graduação em enfermagem descrevem de maneira diferente cada semestre que vivenciam. Os semestres iniciais são caracterizados principalmente por disciplinas teóricas, enquanto que nos mais avançados, os alunos referem sentir uma maior necessidade de domínio das suas emoções em decorrência das aulas práticas e estágios. Mas, apesar disto, a situação em relação a Inteligência Emocional não sofreu muita variação de acordo com os semestreș, pois através do Quadro 1 , podemos perceber que o bom nivel de Inteligência Emocional predominou em todos os periodos. Assim, as colocações dos estudantes são pertinentes, pois o domínio das suas emoções é uma habilidade fundamental para uma competência profissional e plano de enfermagem individualizado, o que fundamentamos em Moscovivi (1997, p.77) que diz: "A competência interpessoal é fundamental na prestação de serviços, pois este profissional trem que lidar com as emoções do cliente, que são reveladas em termos de exigências, expectativas e, ao mesmo tempo, tem que lidar com as suas próprias emoções. A prestação de serviços é uma atividade interpessoal, primordialmente. O serviço será personalizado se houver essa competência interpessoal nos dois lados. É fundamentalmente empatia."

No seu campo de trabalho, seja na assistência ou setor administrativo, o enfermeiro depara-se com um jogo de emoções que precisam ser trabalhadas para não se tornarem obstáculos em seu desempenho. Na assistência, são as emoções do cliente que não podem ser separadas do fator biológico e nem ir de encontro às emoções do profissional. Já no setor administrativo, é a dinâmica de relacionamento interpessoal do trabalho em equipe que muitas 
vezes exige, além da capacidade de liderança, saber agir com a pessoa certa, na medida certa, na hora certa, pelo motivo certo e da maneira certa, como dizia Aristóteles.

Ainda Moscovivi (1997, p. 32) diz que existe nas pessoas dois tipos de competência que se interrelacionam: a competência técnica e a competência interpessoal.

A competência técnica é decorrente de estudo, de conhecimento, de aquisição, de tecnologia, enfim, é a chamada capacitação profissional ou técnica, que é importantissima para qualquer função que se vai exercer na vida, no trabalho. Mas ela năo é suficiente, porque as pessoas trabalham junto com outras pessoas. Ninguém vive só e para adquinimos um equilibrio emocional sejam bem fundamentados, bem exercidos, bem implementados, e isto depende do outro tipo de competência, a interpessoal.

Assim, a Inteligência Emocional é um aprendizado permanente, mas que urge para a sobrevivência para a sobrevivência no mundo moderno, pois se permitirmos que as emoçōes fujam do nosso controle, corremos o risco de analisar a realidade muito subjetivamente, distorcendo as informações e até mesmo tendo um comportamento ineficiente para determinadas situações comuns no dia-a-dia.

PARTE II - Avaliação das Aptidões Emocionais, Cognitivas e Comportamentais

QUADRO 2. Distribuição das aptidões classificadas como suficientes nos periodos da graduação. Fortaleza - CE, 1999.

\begin{tabular}{|c|c|c|c|}
\hline Periodos Aptidaces & $\begin{array}{l}\text { Aptidties } \\
\text { Emocionais }\end{array}$ & Aptidöes Cognitivas & $\begin{array}{l}\text { Aptidíes: } \\
\text { Comportamentais }\end{array}$ \\
\hline 1 período & 07 & 23 & 22 \\
\hline 2 período & 05 & 11 & 08 \\
\hline $3^{\circ}$ periodo & 04 & 07 & 07 \\
\hline 4 periodo & 03 & 12 & 08 \\
\hline 5 periodo & 06 & 17 & 09 \\
\hline 6 periodo & 07 & 14 & 16 \\
\hline $7^{\circ}$ periodo & 04 & 13 & 09 \\
\hline 8 periodo & 08 & 14 & 14 \\
\hline $9^{\circ}$ periodo & 04 & 07 & 06 \\
\hline TOTAL: & 48 & 118 & 99 \\
\hline
\end{tabular}

Através do Quadro 2 podemos perceber que as aptidões que mais se destacaram como suficientes foram as cognitivas (118). Enquanto que as aptidões emocionais foram classificadas como suficientes em 48 sujeitos. Isto demonstra uma predominância maior em sujeitos que tem mais habilidades em usar o pensamento do que em lidar com as emoções. Os participantes da pesquisa que estão incluídos entre os que possuem mais aptidões suficientes cognitivas são caracterizados por Goleman (1995), como pessoas que têm um "diálogo interior", como uma forma de enfrentar o assunto ou reforçar o próprio comportamento; lêem e interpretam indicios sociais e conhecem influências sociais sobre o comportamento e vêem-se na perspectiva da comunidade maior; usam etapas para resolver problemas e tomar decisões, como controlar impulsos, estabelecer metas, identificar ações altemativas e prever conseqüências; compreendem a perspectiva dos outros e normas de comportamento, além de terem uma autoconsciência, que os faz criar expectativas realistas para si mesmos.

Ainda segundo Goleman (1995) existem estruturas anatômicas no Sistema Nervoso Central que são o centro das batalhas ou tratados de cooperação entre a cabeça e o coração, 
o pensamento e o sentimento. Através de ligações entre estas estruturas, estes circuitos explicam por que a emoção é tão crucial para o pensamento efetivo, tanto no tomar decisões sensatas quanto simplesmente permitindo pensar com clareza.

Notamos, também, que de um modo particular no $3^{\circ}$ e $8^{\circ}$ períodos os sujeitos se destacaram com habilidades suficientes não só no aspecto cognitivo, mas também no comportamental, uma vez que se equivalem nos números.

QUADRO 3. Distribuição das aptidões classificadas como regulares nos periodos da graduação. Fortaleza, Ceará, 1999.

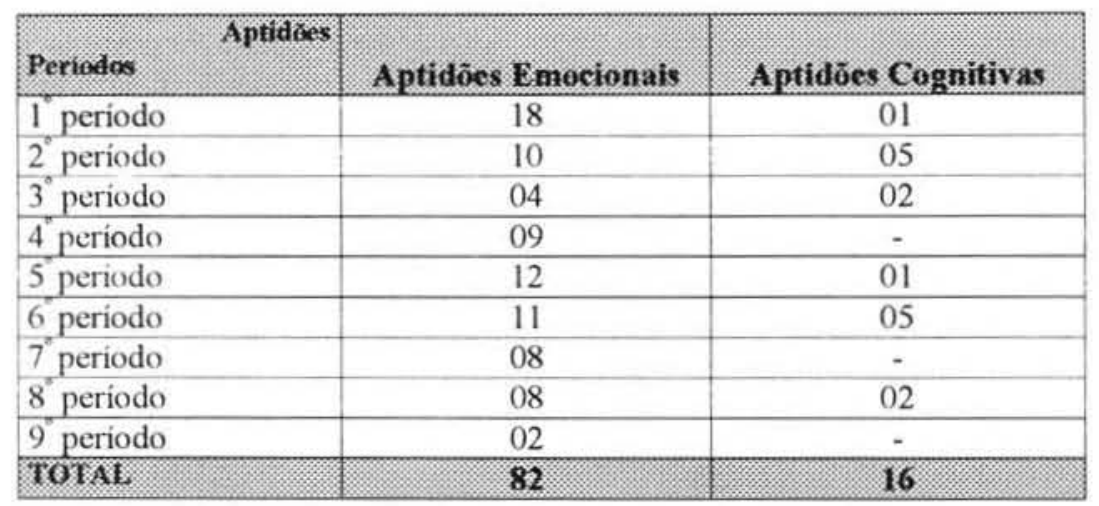

Em complementação com o quadro 2, este nos mostra que os sujeitos quanto as aptidões emocionais, foram mais classificados como regulares (82), indicativo de que são pessoas que regularmente vivem lutando contra sentimentos inquietantes da vida tendo uma recuperação mais lenta que os demais.

Para elevar esta classificação de regular para suficiente seria necessário que estas pessoas conseguissem identificar, rotular e expressar sentimentos, avaliando a intensidade destes; controlassem os impulsos e soubessem a diferença entre sentimentos e ações. Reconhecer um sentimento quando ele ocorre é fundamental para a inteligência emocional. Para um discernimento emocional e uma autocompreensão é preciso a capacidade de controlar sentimentos a todo momento. Já a incapacidade de observar nossos verdadeiros sentimentos nos deixa a mercê destes. Lidar com sentimentos para que sejam apropriados é uma aptidão que se desenvolve na autoconsciência, ou seja, é a capacidade de confortar-se e livrar-se da ansiedade, tristeza ou irritabilidade. (Goleman, 1995).

Entretanto, sabemos que nossa formação básica emocional se faz principalmente ao longo da infância e adolescência através da educação familiar e experiências escolar e grupal. Normalmente os pais e professores não estão devidamente preparados para lidar com os aspectos emocionais das crianças, pois existe uma deficiência na formação que é transmitida ao longo das gerações. Dai a importância de se descobrir entre os acadêmicos de enfermagem como estes se encontram em relação a sua Inteligência Emocional, uma vez que, enquanto futuros profissionais é imprescindivel o gerenciamento das emoções, principalmente por se tratar de uma profissão que trabalha com a vida. 
QUADRO 4. Distribuição das aptidões classificadas como insuficientes nos períodos da graduação. Fortaleza - CE, 1999.

\begin{tabular}{|c|c|c|c|}
\hline Porioitos: & Arotitoses & 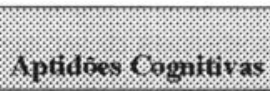 & Comportamenti: \\
\hline 1 período & - & 01 & 03 \\
\hline $2^{\circ}$ período & 01 & - & 08 \\
\hline 3 período & 01 & - & 02 \\
\hline 4 período & - & - & 04 \\
\hline $5^{\circ}$ período & 01 & 01 & 10 \\
\hline $6^{\circ}$ período & 01 & - & 03 \\
\hline $7^{\circ}$ periodo & 01 & - & 04 \\
\hline $8^{\circ}$ período & 02 & 02 & 04 \\
\hline $9^{\circ}$ período & 01 & - & 01 \\
\hline $1001 \% 1$. & 08 & 04. & 39 \\
\hline
\end{tabular}

Embora possamos observar que o número de aptidões insuficientes comportamentais se destaca em relação as demais (39), comparando com o quadro das aptidões suficientes, percebemos que a quantidade de aptidões comportamentais são bem mais significativas (82).

O conjunto das aptidões comportamentais é caracterizado por habilidades não-verbais e verbais que subsidiam e enriquecem o relacionamento interpessoal. Este, por sua vez, é de fundamental importância para o serhumano enquanto ser social, e mais ainda, para a enfermagem, por se caracterizar pelo trabalho em equipe, exigindo continuamente este relacionamento interpessoal. Para o enfermeiro, este aspecto ainda ganha importância quando consideramos as atividades de gerenciamento, de liderança, de organização de grupo, negociação de soluções, empatia e sensibilidade social, características estas como essenciais para o desenvolvimento da inteligência interpessoal. Sobre esta, Antunes (1998, p. 32-3) diz: "A inteligência interpessoal é algo como a intrapessoal, só que para fora. Enquanto que a intrapessoal é a inteligência da auto-estima, auto-respeito e, por analogia, a auto aceitação, a inteligência interpessoal é a maneira como construímos nossas relações com outras pessoas e a forma como nos sentimos contemplados quando em relação a essas pessoas. Existem algumas pessoas que são excelentes, mas que não aceitam muito a vida em grupo. Parece que nasceram para conviver consigo mesmas e assim, na vida profissional, se realizam passando a vida, isoladamente, ( ...) Amam a solidão e sentem-se oprimidos por grupos barulhentos (...) São pessoas que não vivem o mundo "para fora", preferindo cultuar o mundo interior. Essas pessoas possuem inteligência interpessoal pouco desenvolvida...."

Comparando juntamente os quadros que esclarecem, separadamente, as aptidões classificadas como suficientes, regulares e insuficientes, podemos visualizar de uma maneira geral que, as primeiras, que são as que caracterizam os sujeitos da pesquisa em um bom nível com relação às aptidões relacionadas à Inteligência Emocional, são as de número maior. Enquanto que as insuficientes, que classificariam como um nível não satisfatório, tiveram um número menor. Assim, isso deixa a amostra estudada em uma situação favorável a uma boa Inteligência Emocional em relação às aptidões consideradas.

\section{CONSIDERAÇÕES FINAIS}

Apesar de encontrarmos críticas com relação a temática Inteligência Emocional, ressaltamos que tais críticas não contestam a sua existência, mas afirmam que é um conhecimento antigo que está apenas ganhando um novo rótulo. Haver estes julgamentos pode 
significar que embora estejam percebendo que não é um conhecimento novo, estão começando a despertar para sua importância e fundamental necessidade de aplicabilidade nos dias de hoje.

Este estudo nos fez perceber algumas contribuições da Inteligência Emocional para a Enfermagem. Entre elas podemos dizer que, para ampliarmos nossa visão e abarcarmos o impacto das emoçöes, devemos considerar que ajudar as pessoas a lidar melhor com seus sentimentos pertubadores é uma forma de prevenir a doença e reconhecer que os benefícios para o paciente não são advindos somente da satisfação de suas necessidades biológicas, mas também psicológicas. Para isto o enfermeiro precisa manter um ralacionamento empático, ser consciente das suas emoções e das emoções do paciente, lidar com seus sentimentos, sentir o pulso de um grupo, além dos benefícios próprios que o tornam um líder por excelência, exigência constante noas dias atuais para um bom desempenho profissional em um trabalho de equipe.

Quanto a estas características que acabamos de descrever para o enfermeiro, podemos considerar que os acadêmicos de enfermagem estudados demonstraram bom potencial para se tomarem os profissionais assim descritos, pois os resultados apontaram para um bom nivel de Inteligência Emocional e com aptidőes emocionais, cognitivas e comportamentais suficientes para um bom desenvolvimento deste padrão.

No entanto, valendo-nos dos resultados que apontaram para um baixo número de estudantes que tinham Inteligência Emocional superior e um número elevado que mereciam aprimoramento, sugerimos para o ensino de graduação nas escolas de enfermagem que incluam este assunto no programa das disciplinas de psicologia para um maior aprofundamento desta temática e que, nas disciplinas profissionalizantes e estágios, as aptidões sejam melhor exercitadas em todas as suas dimensões, não apenas enfatizando a habilidade técnica.

\begin{abstract}
This study traces the nursing students' profile in order to have a prospective professional vision on the emotional intelligence of these workers. Considering that, nowadays, emotional intelligence is a basic requirement for any kind of profession, this research analysed patterns of cognitive, behavioral and emotional skills among the nursing workers. This is a descriptive exploratory study, accomplished in a public institution in the city of Fortaleza-CE, with 138 students enrolled in the first term of 1999. For this analyses an emotional intelligence questionnaire, available in internet, was applied. The subjects also answered questions related to their behavioral, cognitive and emotional skills. As a result, it was concluded that the majority of the students $(78,26 \%)$ presented a satisfying level of emotional intelligence and only $16,67 \%$ would need improvement. In the classification of the three skills as sufficient, regular and insufficient, the cognitive skill exceeded the other two positivetly. The research showed that students have the basic characteristics of emotional intelligence. They can be in tune and understanding with patients, and also make themselves understood.
\end{abstract}

KEYWORDS: emotional intelligence, nursing education

RESUMEN: Para que tengamos una visión profesional prospectiva, nos hemos propuesto trazar el perfil de los académicos de Enfermeria para obtener un padrón de Inteligencia Emocional e identificar sus aptitudes cognitivas, comportamentales y emocionales, ya que ser emocionalmente inteligente se considera hoy un requisito profesional imprescindible. Estudio exploratorio realizado en una institución pública en Fortaleza-CE entre estudiantes matriculados en 1999/1, entre una muestra de 138 sujetos. Utilizamos un cuestionario disponible en Internet y una segunda parte con preguntas sobre las aptitudes emocionales, cognitivas y comportamentales relacionadas a la Inteligencia Emocional. Como resultado, obtuvimos que la mayoria de los estudiantes -el $78,26 \%$ - tiene un buen nivel de Inteligencia Emocional y el $16,67 \%$ merece un aprimoramiento. Al distribuir las aptitudes 
estudiadas en suficientes, regulares e insuficientes; las cognitivas se han destacado entre las demás. En conclusión, los estudiantes tienen potencial para ser profesionales con empatía, estar sintonizados con los enfermos y ser capaces de saber y hacerse oír, características básicas de la Inteligencia Emocional.

PALABRAS CLAVE: Inteligencia Emocional, educación en enfermería.

\section{REFERÊNCIAS BIBLIOGRÁFICAS}

ANTUNES,C. A inteligência emocional na construção do novo eu. 4.ed. Rio de Janeiro: Vozes, 1998 $84 p$.

CAVICCHINI, A. Inteligência Emocional. Rio de Janeiro: Suma Econômica, 1994.

GOLEMAN, D. Inteligência Emocional: A teoria revolucionária que redefine o que é ser inteligente. 28. ed. Rio de Janeiro: Objetiva, 1995. 375p.

LAKATOS, E.M. , MARCONI, M. de A. Fundamentos de metodologia científica. 3.ed. São Paulo: Atlas, 1991. $270 \mathrm{p}$.

MOSCOVICI, F. Razão e Emoção: a inteligência emocional em questão. 2.ed. Salvador: Casa da Qualidade, 1997. 133p

\section{INSTRUMENTO}

Somos bolsistas do PET/Enfermagem/UECE e estamos estudando a Inteligência Emocional dos estudantes de Enfermagem da Universidade Estadual do Ceará, aspecto fundamental para futuros profissionais. Pedimos a sua participação em responder estes itens com convicção.

Desde já, agradecemos sua colaboração:

Meuda, Laína e Stefânia

PARE, RESPIRE, REFLITA ... Faça uma introspecção, paraficar em sintonia com o seu EU e responda.

\section{PARTE I}

1 - Tenho consciência até mesmo da mais singela das emoções, assim que elas acontecem

$\square$ Sempre $\square$ Normalmente $\square$ As vezes $\square$ Raramente $\square$ Nunca

2 - Uso os meus sentimentos para ajudar a tomar decisões importantes na vida.

[] Sempre $\square$ Normalmente $\square$ As vezes $\square$ Raramente $\square$ Nunca

3 - O mau humor me abate.

$\square$ Sempre $\square$ Normalmente $\square$ As vezes $\square$ Raramente $\square$ Nunca

4 - Quando estou bravo, das duas uma: estouro ou fico remoendo a raiva em silêncio.

Sempre $\square$ Normalmente $\square$ As vezes $\square$ Raramente $\square$ Nunca

5 - Sei esperar por elogios ou gratificações quando alcanço os meus objetivos.

Sempre $\square$ Normalmente $\square$ As vezes $\square$ Raramente $\square$ Nunca

6 - Quando estou ansioso em relação a um desafio, como falar em público ou fazer um teste tenho dificuldade de me preparar adequadamente.

$\square$ Sempre $\square$ Normalmente $\square$ As vezes $\square$ Raramente $\square$ Nunca 
7 - Em vez de desistir diante de obstáculos ou decepções, eu permaneço otimista e esperançoso.

$\square$ Sempre $\square$ Normalmente $\square$ As vezes $\square$ Raramente $\square$ Nunca

8 - As pessoas não precisam me falar o que sentem, posso perceber sozinho.

$\square$ Sempre $\square$ Normalmente $\square$ As vezes $\square$ Raramente $\square$ Nunca

9 - Meu senso afiado pelos sentimentos alheios me faz compreensivo diante dos momentos dificeis dessas pessoas.

$\square$ Sempre $\square$ Normalmente $\square$ As vezes $\square$ Raramente $\square$ Nunca

10 - Tenho problemas para lidar com conflitos e com o baixo astral em relacionamentos.

$\square$ Sempre $\square$ Normalmente $\square$ As vezes $\square$ Raramente $\square$ Nunca

11 - Posso sentir o pulso de um grupo ou de uma relação entre pessoas e expor sentimentos não ditos.

$\square$ Sempre $\square$ Normalmente $\square$ As vezes $\square$ Raramente $\square$ Nunca

12- Posso acalmar ou conter sentimentos aflitivos de forma que isto não me impeça de continuar fazendo as coisas que tenho que fazer.

$\square$ Sempre $\square$ Normalmente $\square$ As vezes $\square$ Raramente $\square$ Nunca

\section{PARTE॥}

Aptidões Emocionais

No seu cotidiano, você ...

Identifica e rotula os sentimentos? $\square$ Sim $\square$ Não

Expressa sentimentos? $\square$ Sim $\square$ Não

Avalia a intensidade dos sentimentos? $\square$ Sim $\square$ Não

Lida com sentimentos? $\square$ Sim $\square$ Não

Adia a satisfação? $\square$ Sim $\square$ Não

Controla impulsos? $\square$ Sim $\square$ Não

Reduz a tensão? $\square$ Sim $\square$ Não

Sabe a diferença entre sentimentos e ações? $\square$ Sim $\square$ Não

Aptidões Cognitivas

Fala consigo mesmo? $\square$ Sim $\square$ Não

Lê e interpreta indicios sociais? $\square$ Sim $\square$ Não

Usa etapas para resolver problemas e tomar decisões? $\square$ Sim $\square$ Não

Compreende a perspectiva dos outros? $\square$ Sim $\square$ Não

Compreende normas de comportamento? $\square$ Sim $\square$ Não

Tem autoconsciência? $\square$ Sim $\square$ Não

Aptidöes Comportamentais

Comunica-se através dos olhos, expressão facial, tom de voz, gestos, etc. ? $\square$ Sim $\square$ Não Faz pedidos claros? $\square$ Sim $\square$ Não

Responde eficientemente à crítica? $\square$ Sim $\square$ Não

Ouve os outros? $\square$ Sim $\square$ Não 